\title{
Cathodoluminescence of zinc oxide crystals grown from melt under high pressure in the presence of ytterbium oxide
}

\author{
A.N. Baranov, ${ }^{1,}{ }^{*}$ M.V. Shestakov, ${ }^{2}$ M.V. Chukichev, ${ }^{3}$ V.A. Tafeenko, ${ }^{1}$ V.A. Mukhanov, ${ }^{1}$ \\ V.L. Solozhenko ${ }^{4}$
}

1 Chemistry Department, Lomonosov Moscow State University, Moscow, 119991, Russia

2 Department of Physics, Russian State Agrarian University, Moscow, 127434, Russia

3 Physics Department, Lomonosov Moscow State University, Moscow, 119991, Russia

4 LSPM-CNRS, Université Sorbonne Paris Nord, 93430 Villetaneuse, France

\begin{abstract}
A mixture of poly- and single crystals of zinc and ytterbium (2 at.\%) oxides have been grown from the melt at high temperature $\left(1430^{\circ} \mathrm{C}\right)$ and high pressure $(3.8 \mathrm{GPa})$. The crystals were transparent under examination with naked eye. The diameter of crystals was in the range from 0.005 to $2 \mathrm{~mm}$. X-ray diffraction confirmed presence of individual zinc and ytterbium oxides in the recovered samples. No change of zinc oxide lattice parameters was observed compared to pristine zinc oxide. Cathodoluminescence spectra of the mixture were recorded at 77 and $293 \mathrm{~K}$. The collected spectra exhibit UV, green and near-infrared bands due to exciton recombination, presence of oxygen vacancies and ytterbium ions in $\mathrm{ZnO}$ crystals, respectively.
\end{abstract}

KEYWORDS: single crystal; polycrystal; zinc oxide; ytterbium; cathodoluminescence

\footnotetext{
*Corresponding author: anb@inorg.chem.msu.ru
} 


\section{INTRODUCTION}

Zinc oxide is one of the most promising semiconductors for solar cell up- and downconverters because it's cheap and appropriate host for lanthanides [1,2]. The lanthanides atoms on $\mathrm{ZnO}$ surface can effectively convert UV and visible light into near-infrared range where the c-Si solar cells strongly absorb light [3-6]. The light conversion can occur through non-radiative energy transfer from excited state of $\mathrm{ZnO}$ to the excited states of lanthanide ions with subsequent light emission in the infrared range [7-9]. The energy transfer is quite an effective process resulting in the efficiency of up to $200 \%$ when quantum cutting takes place [10].

A number of lanthanide-doped $\mathrm{ZnO}$ materials, such as composites, films, nanoparticles etc., has already been reported in literature [7-9,11-13]. However, it's still unclear whether large number of lantanide ions can be dispersed in $\mathrm{ZnO}$ crystalline lattice or the ions can only segregate into crystalline lanthanide oxide due to large charge and radius of trivalent lanthanide ion. Such thermodynamically non-equilibrium method as ion-beam implantation results in the incorporation of lanthanide ions in $\mathrm{ZnO}$ crystalline lattice with its subsequent out diffusion and segregation upon heat treatment $[14,15]$. That fact also raises a question whether the luminescent lanthanide centers located in $\mathrm{ZnO}$ matrix or at interface between zinc and lanthanide oxides [7-9].

This work is a follow-up of our previous article on $\mathrm{ZnO}$ single crystal growth via spontaneous crystallization from high-temperature melts under high pressure [16]. In that work, the grown $\mathrm{ZnO}$ single crystals (up to several millimeters) exhibited strong luminescence in the UV and visible ranges. In the present work, the crystal growth method was adapted for growing a mixture of poly- and single crystals of $\mathrm{ZnO}$ and $\mathrm{Yb}_{2} \mathrm{O}_{3}$, and the recovered samples were studied by scanning electron microscopy (SEM), X-ray diffraction and cathodoluminescence spectroscopy.

\section{MATERIALS AND METHODS}

A mixture of poly- and single crystals of zinc and ytterbium (2 at.\%) oxides have been grown from the melt at $3.8 \mathrm{GPa}$ in a toroid-type high-pressure apparatus [16]. The details of the growth method are described elsewhere [17,18]. Microcrystalline powders of ZnO (Alfa Aesar, 99,9995\%) and $\mathrm{Yb}_{2} \mathrm{O}_{3}$ (Alfa Aesar, 99,99\%) were thoroughly mixed and ground in a mortar, then pressed into a pellet and placed into a special gold capsule. The $\mathrm{ZnO}: \mathrm{Yb}_{2} \mathrm{O}_{3}$ molar ratio was equal to 50:1. The samples were gradually compressed up to $3.8 \mathrm{GPa}$ and heated up to $1430^{\circ} \mathrm{C}$ with an average rate $500^{\circ} \mathrm{C} / \mathrm{min}$, annealed at this temperature for $2 \mathrm{~min}$ and cooled down to $1100^{\circ} \mathrm{C}$ with an average rate $90^{\circ} \mathrm{C} / \mathrm{min}$. Crystallization of the melt was observed in the 
temperature range from 1290 to $1250^{\circ} \mathrm{C}$, as evidenced by an increase of electrical resistance of the high-pressure cell. Finally, the sample was quenched down to room temperature and slowly decompressed. The recovered pellet comprised of a mixture of transparent greenish-yellow crystals with diameters from 0.005 to $0.2 \mathrm{~mm}$.

The morphology and elemental composition of the samples were examined using a LEO Supra 50 VP (Carl Zeiss) high resolution scanning electron microscope equipped with an energydispersive X-ray detector.

The single crystal and powder X-ray diffraction studies were performed using STADIVARI PILATUS100K equipped with a semiconductor detector. The collected patterns were analyzed with WINPLOTR software.

The cathodoluminescence (CL) spectra were measured with a custom-made setup equipped with a pulsed "electron gun" and vacuum cryostat $\left(5 \times 10^{-7} \mathrm{~mm} \mathrm{Hg}\right)$. The spectra were recorded using a diffraction grating spectrometer (dispersion $5 \AA / \mathrm{mm}$ ) and synchronous detector at temperatures of 77 and $300 \mathrm{~K}$. The current and energy varied within $0.05-2 \mathrm{~mA}$ and $10-50 \mathrm{keV}$ ranges, respectively.

\section{RESULTS AND DISCUSSION}

The peculiarities of heat dissipation by a top plate and a low piston of in the hydraulic press result in the temperature gradient in high-pressure cell of the toroid-type apparatus. The value of the temperature gradient is approximately $10-20^{\circ} \mathrm{C} / \mathrm{mm}$ at $1430^{\circ} \mathrm{C}$ and $3.8 \mathrm{GPa}$. That temperature gradient plays a significant role in the process of $\mathrm{ZnO}$ crystal growth from the melt. Upon quenching, the crystallization process immediately starts in the top relatively cold part of the cell resulting in a disordered layer of $\mathrm{ZnO}$ polycrystals. Further, these polycrystals act as seeds for the crystal growth. Upon further temperature decrease, the $\mathrm{ZnO}$ crystals continue to grow along the temperature gradient forming a batch of needle-like crystals.

The crystal growth process changes in the presence of $\mathrm{Yb}_{2} \mathrm{O}_{3}$ in the initial mixture. Under high pressure and temperature, $\mathrm{Yb}_{2} \mathrm{O}_{3}$ dissolves in the $\mathrm{ZnO}$ melt. Upon quenching $\mathrm{Yb}_{2} \mathrm{O}_{3}$ crystallizes first forming a layer of polycrystals. The $\mathrm{Yb}_{2} \mathrm{O}_{3}$ polycrystals act as seeds for subsequent growth of $\mathrm{ZnO}$ single crystals.

Fig. 1(a,b) show SEM images of single and multiple $\mathrm{ZnO}: \mathrm{Yb}_{2} \mathrm{O}_{3}$ crystals. One can see large irregular crystals of $\mathrm{ZnO}$ with diameters varying from tens of micrometers to $0.1 \mathrm{~mm}$. The small inclusions of $\mathrm{Yb}_{2} \mathrm{O}_{3}$ crystals are seen on the surface of large $\mathrm{ZnO}$ crystals (Fig. 1c). The SEM 


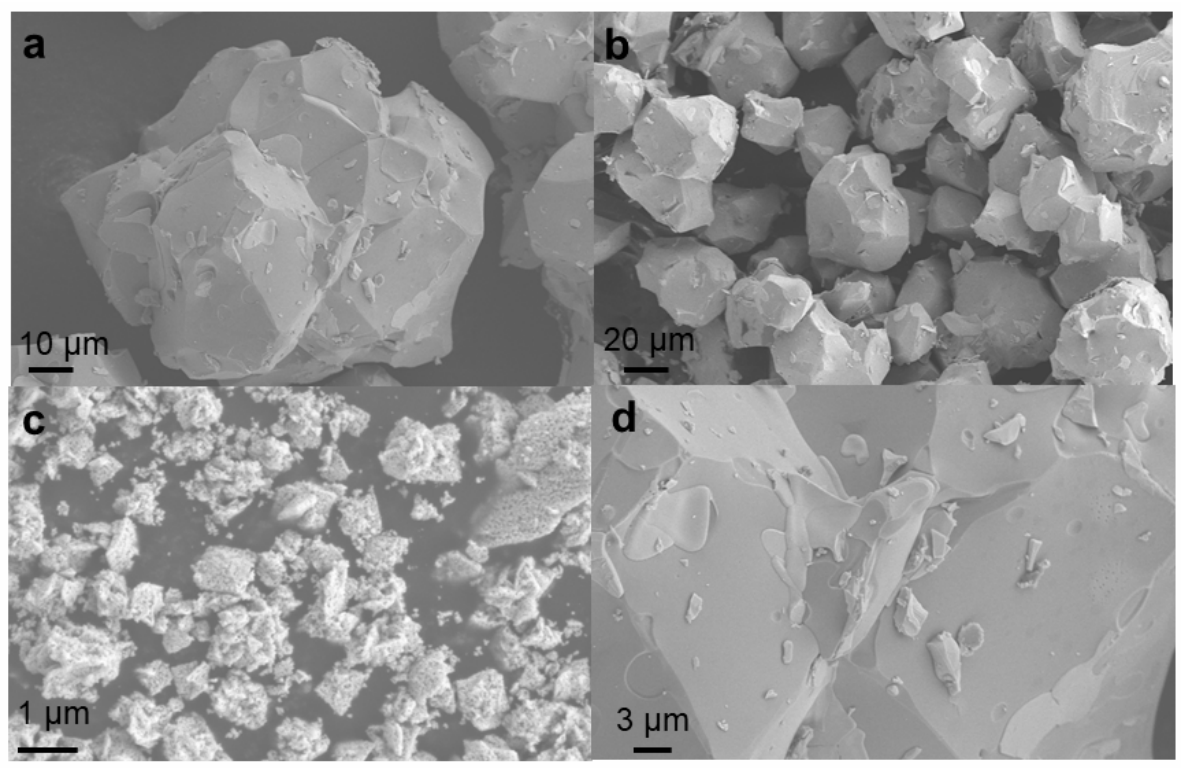

Figure 1 SEM images of $\mathrm{ZnO}: \mathrm{Yb}_{2} \mathrm{O}_{3}$ single crystals $(a, b)$, and $\mathrm{Yb}_{2} \mathrm{O}_{3}$ single crystals (initial $(c)$ and after crystallization from the melt $(d)$ ).

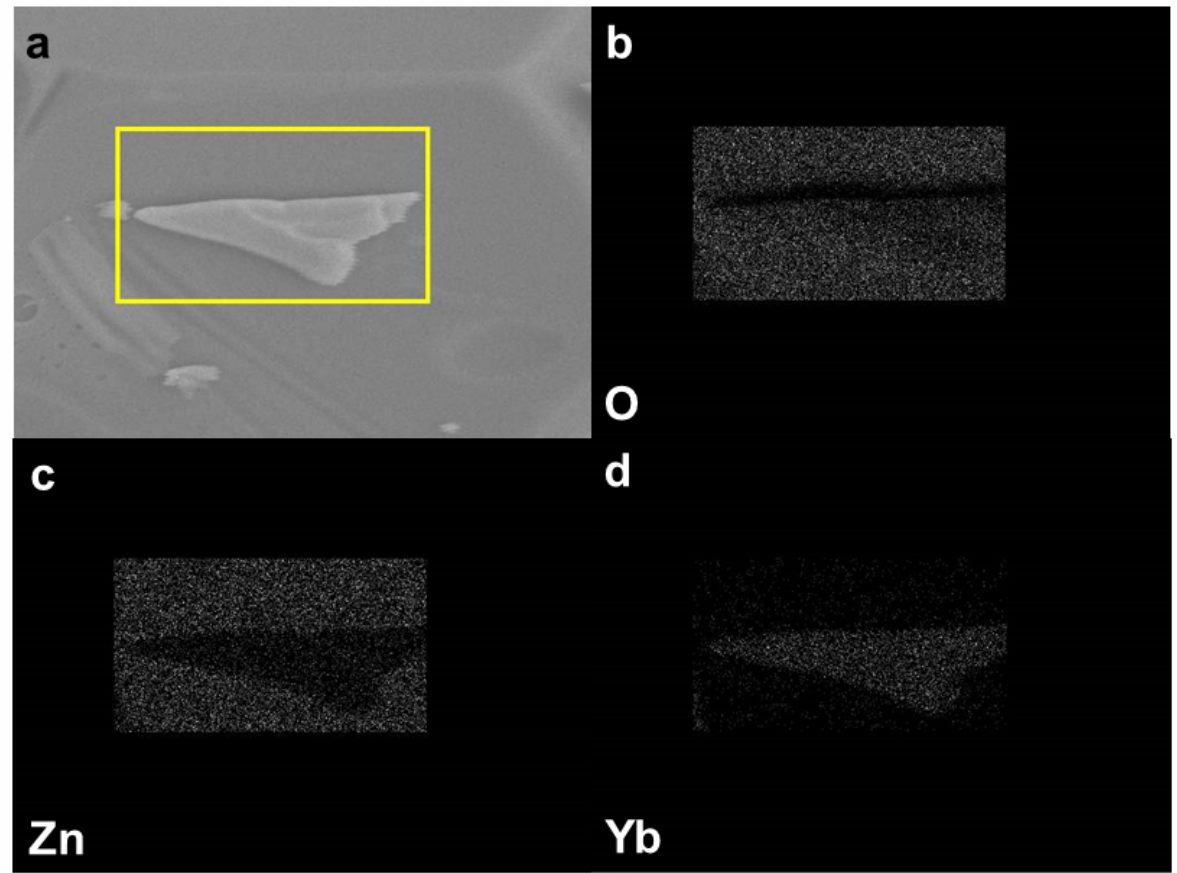

Figure 2 SEM images of $\mathrm{ZnO}: \mathrm{Yb}_{2} \mathrm{O}_{3}$ single crystal $(a)$ with the area selected for EDX mapping of oxygen $(b)$, zinc $(c)$ and ytterbium $(d)$. 
image of initial $\mathrm{Yb}_{2} \mathrm{O}_{3}$ crystals is shown in Fig. 1d. They are irregular with diameters much smaller than $1 \mu \mathrm{m}$. After crystallization from the melt, $\mathrm{Yb}_{2} \mathrm{O}_{3}$ crystals become enlarged and grow on the surface of $\mathrm{ZnO}$ single crystals. Therefore, the obtained SEM images confirm our hypotheses on the change of crystal growth process after addition of $\mathrm{Yb}_{2} \mathrm{O}_{3}$ crystals to the melt.

Fig. 2 demonstrates SEM image of $\mathrm{ZnO}: \mathrm{Yb}_{2} \mathrm{O}_{3}$ single crystal area with corresponding elemental maps. The EDX analysis shows that the irregular crystal mostly comprises of $\mathrm{Zn}$ and $\mathrm{O}$ atoms. The small surface inclusion comprises of $\mathrm{Yb}$ and $\mathrm{O}$ atoms. Therefore, the EDX analysis supports our hypothesis of very limited (below $0.2 \%$ ) solubility of $\mathrm{Yb}_{2} \mathrm{O}_{3}$ in $\mathrm{ZnO}$.

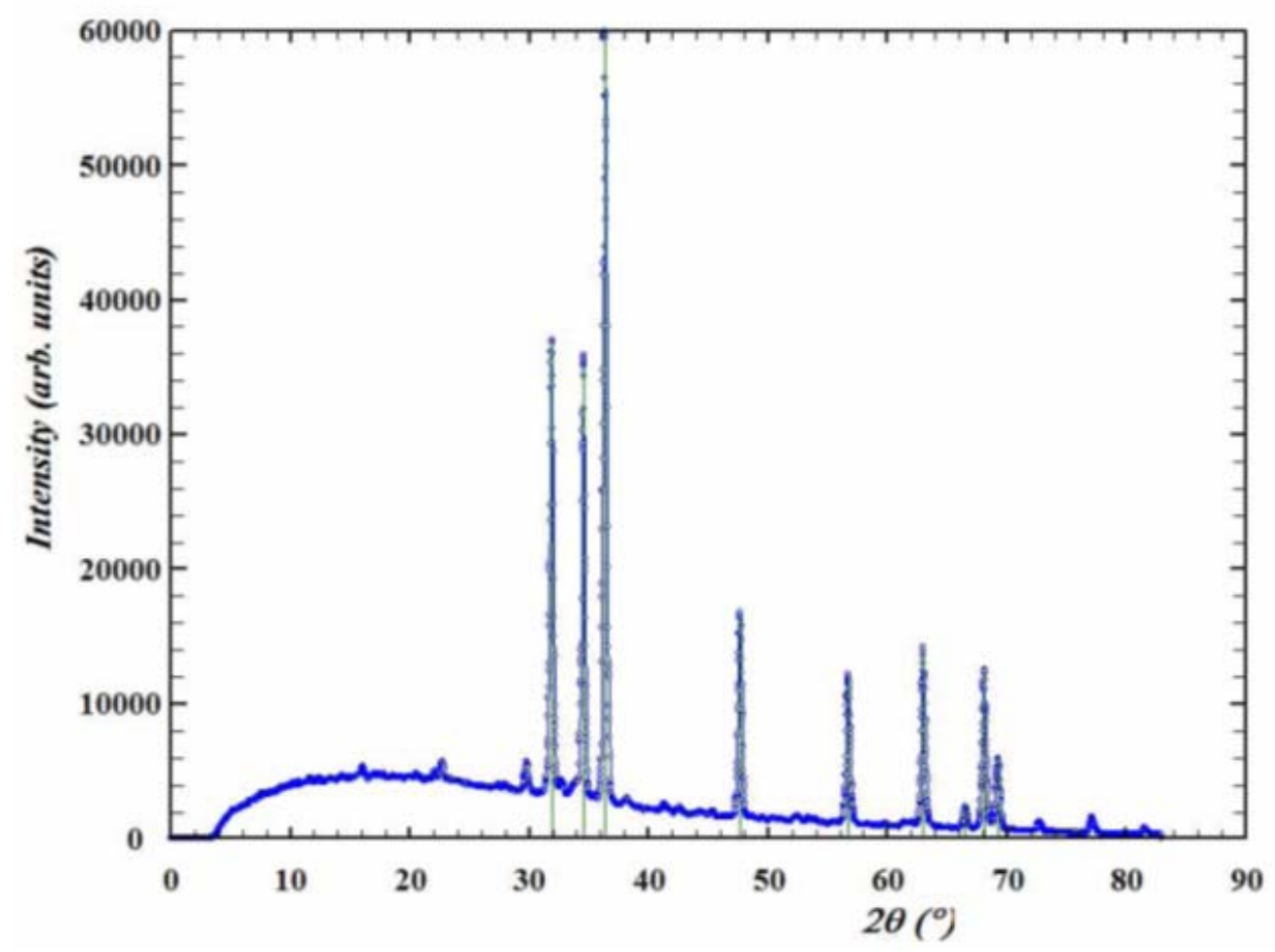

Figure 3 Powder X-ray diffraction pattern of $\mathrm{ZnO}: \mathrm{Yb}_{2} \mathrm{O}_{3}$ crystals

Powder X-ray diffraction pattern of $\mathrm{ZnO}: \mathrm{Yb}_{2} \mathrm{O}_{3}$ crystals is shown in Fig. 3. The pattern contains the reflections corresponding to wurtzite $\mathrm{ZnO}$ and cubic $\mathrm{Yb}_{2} \mathrm{O}_{3}$. The $\mathrm{ZnO}$ reflections were indexed with ICDD PDF-2 [36-1451] card and indicated by green bars. The lattice constants of $\mathrm{ZnO}$ crystals were determined from powder and single-crystal X-ray diffraction data (Table 1). The obtained values are in good agreement with ICDD PDF-2 [36-1451] card for pure ZnO indicating a low doping level of $\mathrm{ZnO}$ by $\mathrm{Yb}$. 
Table $1 \mathrm{ZnO}$ unit cell parameters calculated from X-ray diffraction data

\begin{tabular}{|c|c|c|c|}
\hline X-ray diffraction & $a=b, \AA$ & $c, \AA$ & $\mathrm{V}, \AA^{3}$ \\
\hline powder & $3.248(2)$ & $5.206(2)$ & 47.48 \\
\hline single crystal & $3.2503(6)$ & $5.2068(9)$ & $47.64(1)$ \\
\hline
\end{tabular}

Fig. 4 shows cathodoluminescence spectrum of undoped $\mathrm{ZnO}$ single crystal at room temperature. The excitation of zinc oxide with electrons results in typical UV and green emission bands located in the ranges $350-430 \mathrm{~nm}$ and $450-600 \mathrm{~nm}$, respectively. The UV emission is due to radiative recombination of free and bound excitons [19]. The green emission band is associated with various intrinsic defect centers, such as oxygen or zinc vacancies, in $\mathrm{ZnO}$ emerging during the synthesis [20].

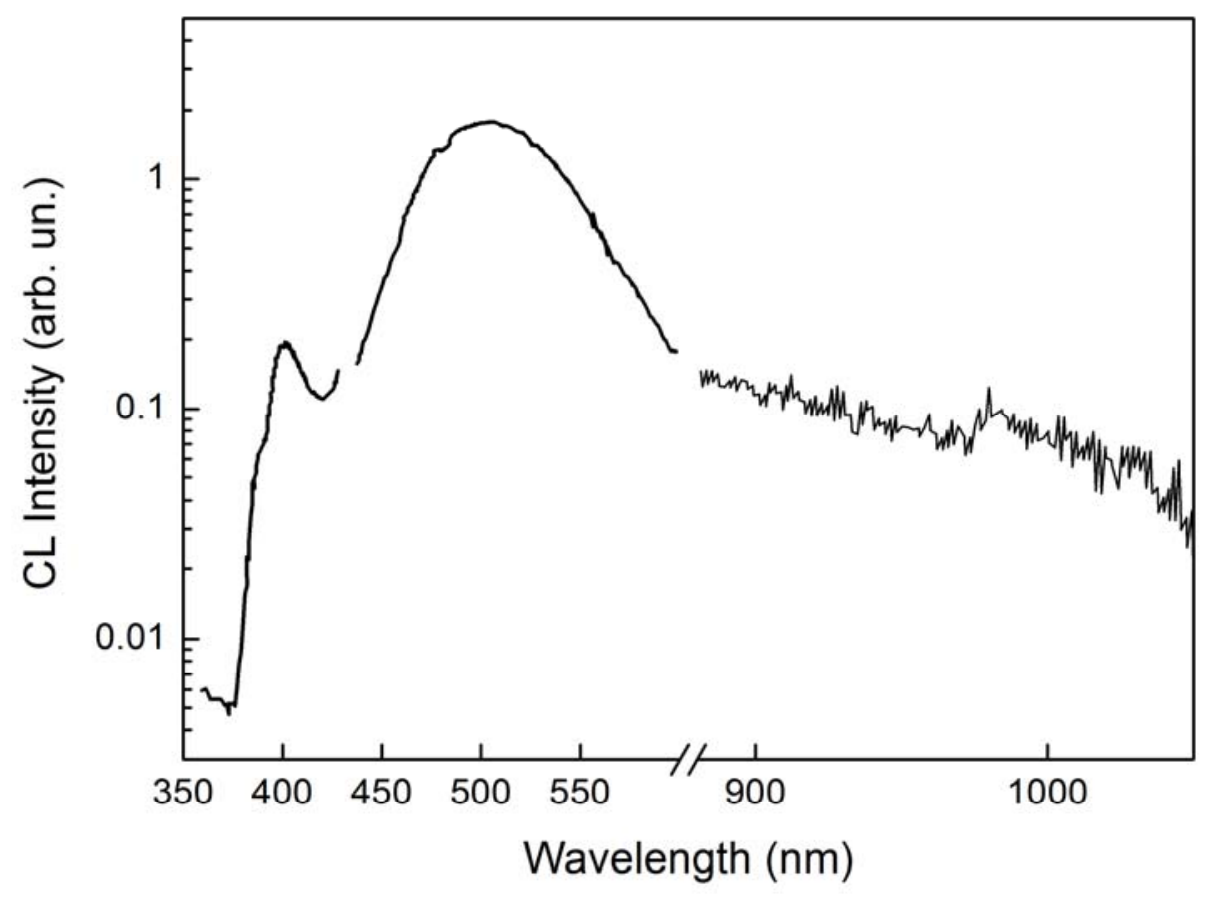

Fig. 4 Cathodoluminescence of undoped $\mathrm{ZnO}$ crystal at room temperature

Fig. 5 shows cathodoluminescence spectrum of $\mathrm{ZnO}: \mathrm{Yb}_{2} \mathrm{O}_{3}$ single crystals at room and liquid nitrogen temperatures. One can see the UV and visible bands similar to the undoped $\mathrm{ZnO}$, and an 
infrared band located at $980 \mathrm{~nm}$. Upon addition of $\mathrm{Yb}_{2} \mathrm{O}_{3}$ to $\mathrm{ZnO}$, the intensity of exciton luminescence decreases while the intensity of green luminescence is virtually unchanged. The infrared band emerges due to radiative electron transition from ${ }^{2} \mathrm{~F}_{5 / 2}$ excited state to ${ }^{2} \mathrm{~F}_{7 / 2}$ ground state in $\mathrm{Yb}^{3+}$ ions [7-9]. The intensity of the infrared cathodoluminescence drastically increases upon cooling down the single crystals down to liquid nitrogen temperature. The infrared luminescence band slightly red-shifts, possibly due to the change in electron population of the excited and ground states.

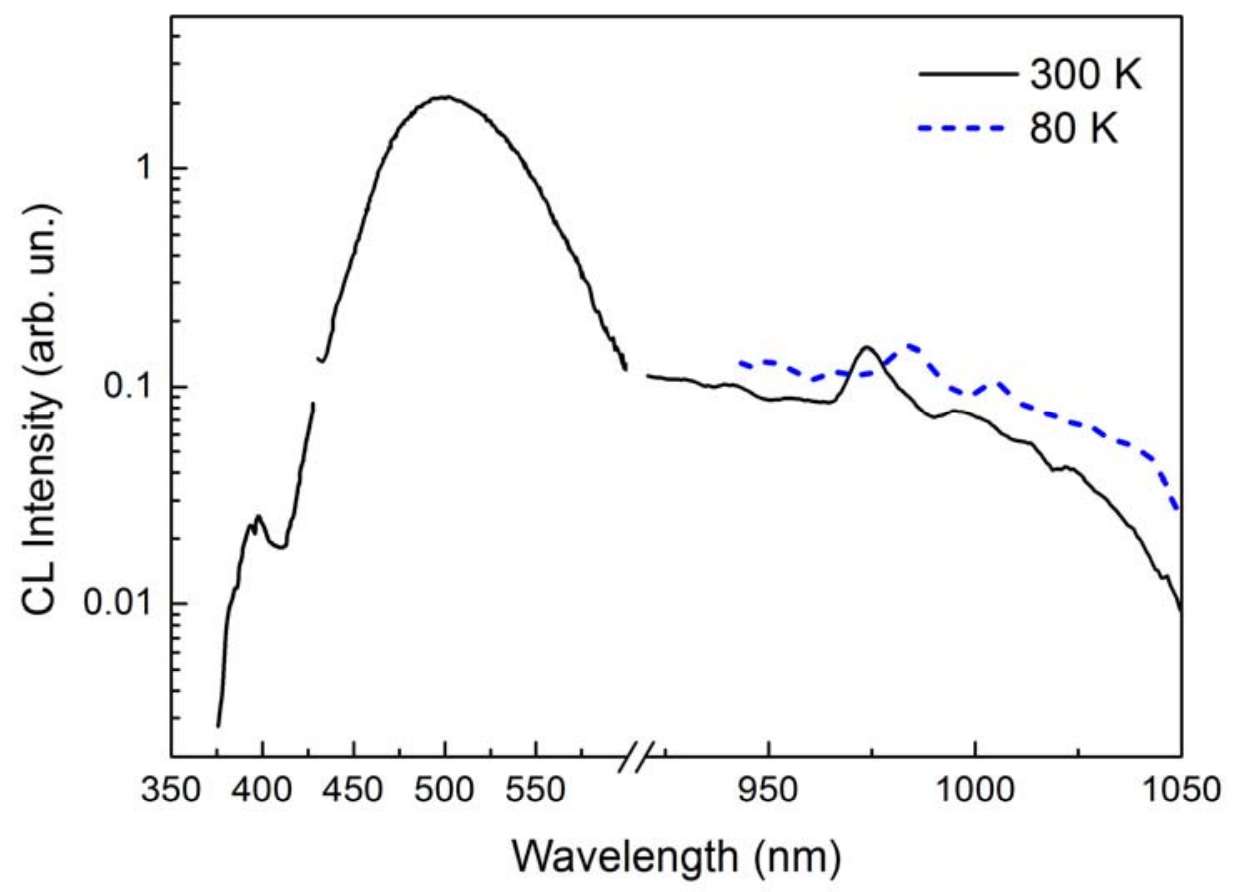

Figure 5 Cathodoluminescence of undoped $\mathrm{ZnO}: \mathrm{Yb}_{2} \mathrm{O}_{3}$ crystal at different temperatures.

Earlier we reported the synthesis of $\mathrm{ZnO} / \mathrm{Yb}_{2} \mathrm{O}_{3}$ composite for solar spectrum down-conversion [7]. The composite consisted of $\mathrm{ZnO}$ nanocrystals with attached tiny $\mathrm{Yb}_{2} \mathrm{O}_{3}$ nanoparticles. Upon excitation with UV-light, the composite emitted light in the visible and infrared ranges with spectra quite similar to the reported in present paper. The energy transfer from $\mathrm{ZnO}$ exciton to $\mathrm{Yb}^{3+}$ ions was proposed as possible mechanism of the observed infrared photoluminescence. It's highly likely that similar mechanism of the energy transfer is involved in the infrared cathodoluminescence of $\mathrm{ZnO}: \mathrm{Yb}_{2} \mathrm{O}_{3}$ single crystals. As $\mathrm{Yb}_{2} \mathrm{O}_{3}$ single crystals are ingrown into $\mathrm{ZnO}$ single crystals, the energy transfer can occur at the interface of two crystal lattices. Further, 
the $\mathrm{ZnO}: \mathrm{Yb}_{2} \mathrm{O}_{3}$ single crystals may be milled in a planetary mill, encapsulated into a PMMA layer and deposited onto surface of c-Si solar cell for investigation of its efficiency improvement.

\section{CONCLUSIONS}

The method of crystal growth from the melt at high pressure was applied for growth of a mixture of poly- and single crystals of zinc and ytterbium oxides. SEM examination revealed that small $\mathrm{Yb}_{2} \mathrm{O}_{3}$ particles grow on the surface of the resultant $\mathrm{ZnO}$ single crystals and act as seeds in the crystallization process. Under electron excitation $\mathrm{ZnO}: \mathrm{Yb}_{2} \mathrm{O}_{3}$ crystals emit light in $\mathrm{UV}$, visible and infrared ranges. The infrared cathodoluminescence $(\sim 985 \mathrm{~nm})$ is associated with possible energy transfer from $\mathrm{ZnO}$ crystalline host to $\mathrm{Yb}_{2} \mathrm{O}_{3}$ ingrown particles.

\section{ACKNOWLEDGEMENTS}

ANB is grateful to the Université Sorbonne Paris Cite for financial support. The work was supported by the RF President Grant for Leading Scientific Schools (Grant Number 2726.2020.3). The authors acknowledge support from Lomonosov Moscow State University Program of Development for providing access to the XRD and SEM facilities.

\section{CONFLICT OF INTERESTS}

The authors declare no conflict of interests.

\section{ORCID IDs}

Vladimir L. Solozhenko (b) https://orcid.org/0000-0002-0881-9761 


\section{REFERENCES}

1. Shohany B.G., Zak A.K., 2020, Ceram. Int., 46, 5507.

2. Marin R., Jaque D., 2021, Chem. Soc. Rev., 121, 1425.

3. Karunakaran S.K., Arumugam G.M., Yang W., Ge S., Khan S.N., Lin X., Yang G., 2021, ACS Sustainable Chem. Eng., 9, 1035-1060.

4. Swart H.C., 2019, Proc. SPIE, 11043, 1104302.

5. Chen D., Wang Y., Hong M., 2012, Nano Energy, 1, 73.

6. Huang X., Han S., Huang W., Liu X., 2013, Chem. Soc. Rev., 42, 173.

7. Shestakov M.V., Baranov A.N., Tikhomirov V.K., Zubavichus Y.V., Kuznetsov A.S., Veligzhanin A. A., Kharin A.Yu., Rösslhuber R., Timoshenko V.Yu., Moshchalkov V.V., 2012, RSC adv., 2, 8783.

8. Shestakov M.V., Tikhomirov V.K., Kirilenko D., Kuznetsov A.S., Chibotaru L.F., Baranov A.N., van Tendeloo G., Moshchalkov V.V., 2011, Optics Express, 19, 15955.

9. Ye S., Jiang N., He F., Liu X., Zhu B., Teng Y., Qiu J.R., 2010, Opt. Express, 18, 639.

10. Rodríguez V.D., Tikhomirov V.K., Méndez-Ramos J., Yanes A.C., Moshchalkov V.V., 2010, Sol. Energy Mater Sol. Cells, 94, 1612.

11. Shalygina O. A., Nazarov I.V., Baranov A.N., Timoshenko V.Yu., 2017, J. Sol-Gel Sci. Technol., 81, 333.

12. Kalaiezhily R. K., Asvini V., Saravanan G., Ravichandran K., 2019, Dalton Trans., 48, 12228.

13. Heng C.L., Wang T., Su W.Y., Wu H.C., Yang M.C., Deng L.G., Yin P.G., Finstad T.G., 2017, J. Alloys Compd., 695, 2232.

14. Nekvindová P., Cajzl J., Macková A., Malinský P., Oswald J., Böttger R., Yatskiv R., 2020, J. Alloys Compd., 816, 152455.

15. Miranda S., Peres M., Monteiro T., Alves E., Sun H., Geruschke T., Vianden R., Loren K., 2011, Opt. Mater., 33, 1139.

16. Mukhanov V.A., Sokolov P.S., Baranov A.N., Timoshenko V.Yu., Zhigunov D.M., Solozhenko V.L., 2013, CrystEngComm, 15, 6318.

17. Baranov A.N., Sokolov P.S., Kurakevych O.O., Tafeenko V.A., Trots D., Solozhenko V.L., 2008, High Pressure Res., 28, 515,

18. Mukhanov V. A., Sokolov P. S., Solozhenko V. L., 2012, J. Superhard Mater., 34, 211

19. Witkowski B.S., Wachnicki L., Gieraltowska S., Reszka A., Kowalski, B.J., Godlewski M., 2015, Microsc. Microanal., 21, 564.

20. Nagase T., Kominami H., Nakanishi Y., Shinozaki K., Mizutani N., 2010, Thin Solid Films, 518, 3875. 